\title{
Desain Aplikasi B2B Sistem Manajemen Pergudangan dalam Penunjang Keputusan Bisnis
}

\author{
Ahmad Roihan*1, Abdul Hamid Arribathi ${ }^{2}$, Nurussaadah ${ }^{3}$ \\ ${ }^{1}$ Program Studi Sistem Komputer STMIK Raharja, ${ }^{2,3}$ Program Studi Sistem Informasi STMIK \\ Raharja \\ Email: *1ahmad.roihan@ raharja.info, $\underline{\text { a abdulhamid@ raharja.info, }}, \underline{{ }^{3} \text { nurussaadah@ raharja.info }}$
}

\begin{abstract}
Abstrak
Pengelolaan data pergudangan berdasarkan produk yang masuk dan keluar dari jasa ekspedisi di PT. Super Tata Raya Steel memiliki beberapa kendala dalam penyampaian informasi. Manajemen data yang dilakukan oleh bagian gudang pada perusahaan masih manual, terutama dalam hal sistem pencatatan dan pembukuan penerimaan dan pengiriman produk. Dalam menangani masalah tersebut, penelitian ini menggunakan beberapa tahap metode antara lain metode observasi, analisis, perencanaan dan desain dengan pendekatan berorientasi pada objek yang menggunakan UML (Unified Modeling Language). Sehingga penelitian ini dapat mengembangkannya ke dalam perancangan sistem dalam bentuk aplikasi berbasis web dengan menggunakan bahasa pemrograman PHP dan MySQL. Keberadaan sistem baru bertujuan untuk mendukung B2B antara layanan ekspedisi dengan perusahaan dan untuk mengurangi terjadinya kesalahan selama pengolahan data pergudangan kemudian manajemen data menjadi lebih cepat dan lebih akurat sehingga laporan yang dihasilkan sesuai dengan data yang ada. Oleh karena itu, penelitian ini dapat digunakan sebagai dukungan untuk keputusan pimpinan dalam menentukan pola bisnis di sektor pergudangan, sehingga pengelolaan layanan perusahaan menjadi efektif dan efisien.
\end{abstract}

Kata Kunci-Manajemen data, gudang, jasa ekspedisi, B2B

\begin{abstract}
Warehousing data processing based on products entering and leaving the expedition in Super Tata Raya Steel companies has several obstacles in the delivery of information. Data management carried out by the warehouse section of the company is still manual, especially in terms of the recording and bookkeeping system of product receipts and shipments. In dealing with these problems, this research uses several stages among observation, analysis, planning and design methods with object-oriented approaches that use UML (Unified Modeling Language). So that this research can develop it into a system design in the form of web-based applications using the PHP and MySQL programming languages. The existence of a new system aims to support business-to-business between the expedition services with the company and to reduce the occurrence of errors during warehousing data processing then data management becomes faster and more accurate so that the resulting report is in accordance with the existing data. Therefore, this research can be used as a support for the leadership's decision in determining business patterns in the warehousing sector, so management of company services become effective and efficient.
\end{abstract}

Keywords-Data management, warehouse, expedition, business-to-business 


\section{PENDAHULUAN}

Teknologi saat ini berkembang sangat cepat. Hal ini diikuti oleh perkembangan teknologi informasi dalam penyampaian aplikasi yang sering disebut sebagai sistem informasi. Pengembangan sistem informasi membutuhkan berbagai faktor pendukung, baik dilihat dari aplikasi dan partisipasi pengguna. Dalam membangun aplikasi, beberapa hal diperlukan untuk membuatnya terlihat lebih sederhana dan lebih menarik bagi pengunjung sehingga partisipasi pengguna diharapkan untuk mendukung keberhasilan sistem informasi yang menghasilkan tingkat kepuasan pengguna sistem informasi dan penyedia aplikasi [1].

Super Tata Raya Steel adalah perusahaan yang bergerak di bidang industri yang memproduksi pipa baja yang merupakan barang setengah jadi yang dipesan langsung oleh pelanggan sesuai dengan kebutuhan. Pada prinsipnya, pengelolaan manajemen arsip data produk yang akurat adalah hal utama untuk menjadi tujuan yang harus dicapai dalam meningkatkan kepuasan dalam memperoleh informasi dan mendukung keputusan untuk pemimpin perusahaan. Oleh karena itu diperlukan sistem yang lebih baik sehingga para pemimpin dan karyawan mendapatkan informasi berharga dari semua data yang tersedia.

Sistem yang dijalankan sebelumnya pada perusahaan Super Tata Raya Steel masih manual karena tidak ada sistem yang mendukung pengolahan data untuk manajemen data produk yang masuk dan keluar yang terkomputerisasi dengan baik, sehingga dapat memakan waktu lama untuk mencari tahu informasi berdasarkan data, maka ini dapat menyebabkan data yang dibutuhkan oleh pimpinan dan karyawan menjadi kurang akurat.

Berdasarkan hasil observasi dan wawancara yang telah dilakukan, masalah yang dihadapi dalam sistem saat ini adalah sistem pengarsipan dokumen produk yang masuk dan keluar yang di bagian layanan ekspedisi dan gudang perusahaan Super Tata Raya Steel terbatas untuk menggunakan program aplikasi sederhana dan melakukan pencatatan manual pada buku besar atau buku agenda, karena tidak adanya sistem informasi. Selanjutnya, dalam penyimpanan data masih belum tertata dengan baik karena tidak adanya penyimpanan data yang kompeten, sehingga dapat menyebabkan kesalahan dalam posisi pengarsipan dokumen, maka sering hilangnya file yang mengakibatkan hasil laporan tidak akurat. Membuat laporan yang masih menggunakan program aplikasi sederhana, memungkinkan terjadinya kesalahan dalam memasukkan data dan kegiatan ini membutuhkan waktu yang lama dalam penyajian informasi dan tentu saja dalam pembuatan laporan akan menjadi sulit dan akhirnya menjadi kurang efektif dan efisien.

Dalam mengatasi masalah yang ada dalam perusahaan tersebut, penelitian ini bermaksud untuk membuat sistem atau aplikasi khusus untuk memasukkan data secara otomatis yang dapat memfasilitasi semua pihak sehingga data dalam penyampaian informasi lebih akurat bagi para pemimpin, karyawan dan layanan ekspedisi. Sehingga semua data dapat diakses dengan mudah dan cepat.

Agar pembahasan pemecahan masalah ini lebih jelas dan akurat, penelitian ini membatasi masalah dengan membuat ruang lingkup penelitian, yaitu dengan menganalisis pengolahan data baik dari data pengiriman produk maupun penerimaan dari layanan ekspedisi mulai dari nama pengemudi, nomor kendaraan, jam masuk, waktu kendaraan, agen atau perusahaan layanan ekspedisi, tanggal dan jenis produk yang dibawa oleh mobil.

Tujuan dari penelitian ini adalah untuk menyederhanakan dan mempercepat kinerja dalam pengelolaan data penerimaan produk di perusahaan Super Tata Raya Steel. Maka sistem yang dibangun dapat memiliki peran yang lebih penting dan mendukung keputusan pemimpin dan dapat menampilkan laporan yang lebih akurat dan real time.

\section{METODE PENELITIAN}

Metode penelitian adalah cara atau langkah yang digunakan dalam melakukan penelitian. Penelitian ini memiliki desain penelitian secara spesifik. Desain menggambarkan prosedur atau langkah yang harus diambil, waktu penelitian, sumber data dan kondisi data yang 
dikumpulkan dan dengan cara apa data dikumpulkan dan diproses untuk digunakan dalam pembuatan laporan.

Terdapat beberapa metode penelitian yang digunakan dalam pembuatan penelitian ini, metode pertama adalah pengumpulan data di perusahaan. Penelitian ini melalui tahap awal pembuatan observasi untuk mengumpulkan data yang dapat mendukung informasi penelitian dalam menganalisis dan pemecahan masalah. Metode pengumpulan data lainnya adalah tinjauan literatur berbagai bahan baik melalui literatur buku dan tulisan atau artikel ilmiah dari beberapa jurnal internasional sebagai pelengkap data penelitian. Selain itu ada dokumen dan data dari bagian pergudangan yang bisa dijadikan sampling data. Semua sumber data dikumpulkan untuk tujuan penelitian yang pada akhirnya akan menguntungkan perusahaan agar dapat berkembang dan maju.

Penelitian ini merupakan pengembangan dari beberapa penelitian sebelumnya terkait. Objek penelitian hanya terbatas pada perusahaan Super Tata Raya Steel. Penelitian saat ini terkait dengan desain dan penerapan bisnis untuk platform bisnis, perdagangan elektronik dan sistem manajemen gudang. Beberapa penelitian telah dilakukan terkait dengan penelitian ini antara lain:

1. Penelitian oleh Michael Goul yang mengungkapkan studi kasus terhadap layanan-layanan dan perkembangan Business Intelligence (BI) [2].

2. Penelitian oleh Kai-Han Yang, dalam penelitiaannya mempelajari pertumbuhan B2B dari perusahaan grosir tradisional [3].

3. Penelitian lainnya membahas tentang WMS (Warehouse Management System) dalam permasalahan yang ada seperti proses optimalisasi pemilihan gudang yang dapat dipecahkan dengan metode optimasi heuristik oleh Emir Zunic [4].

4. Penelitian dari Hendra yang membahas tingkat kepuasan $\mathrm{C} 2 \mathrm{C}$ yang ada di Indonesia dengan pendekatan analisa statistik [5].

5. Penelitian oleh Ahmad Roihan yang membahas penerapan knowledge management dengan sistem aplikasi yang berbasis website sebagai sarana knowledge sharing pada bengkel service kendaraan sekolah menengah kejuruan [6].

6. Penelitian oleh Ribeiro membahas tentang $\mathrm{B} 2 \mathrm{~B}$ dan domain e-Commerce dengan praktik yang baik dan sistem informasi yang mendukung. Setelah itu, daftar persyaratan fungsional dan non-fungsional, yang telah divalidasi dan diprioritaskan juga dibahas dengan menggunakan pendekatan studi kasus [7].

Langkah selanjutnya adalah survei koresponden atau pihak yang terlibat dalam penelitian. Koresponden ditanya pertanyaan terkait dengan kondisi dan masalah di bagian gudang perusahaan, dan selanjutnya berkomunikasi kepada beberapa layanan ekspedisi. Wawancara adalah metode untuk mengumpulkan data melalui komunikasi antar individu sehingga akan mendapatkan informasi untuk digunakan sebagai panduan penelitian.

B2B (business-to-business) adalah salah satu dari 3 kategori dalam perdagangan elektronik, yang merupakan transaksi yang dilakukan antara bisnis di Web [8]. Tenaga penjual yang menggunakan komputer laptop dapat tetap berhubungan dengan pelanggan, menyiapkan penawaran, dan memeriksa pesanan yang dipenuhi dari mana saja. Teknologi internet diintegrasikan ke dalam transaksi B2B dan proses bisnis internal dengan menggunakan kode batang (barcode) dan pemindai untuk melacak bagian, rakitan, inventaris, dan status produksi [9]. 


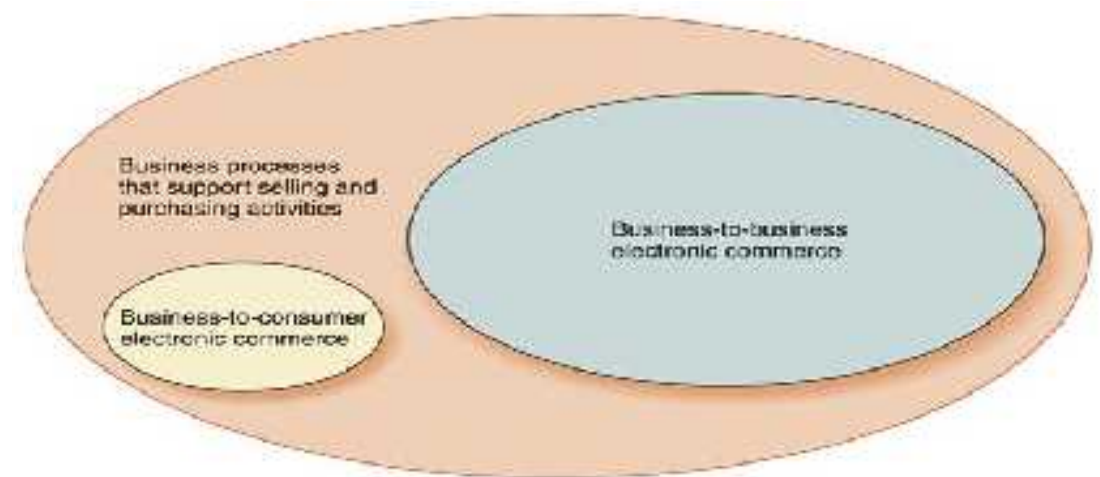

Gambar 1. Elemen-elemen electronic commerce

\section{HASIL DAN PEMBAHASAN}

Berdasarkan pengamatan sebelumnya terhadap beberapa masalah yang terjadi pada sistem yang sedang berjalan di perusahaan, penelitian ini memberikan solusi berupa solusi alternatif terhadap masalah yang dihadapi dengan membuat aplikasi B2B yang dapat membantu dan memudahkan kegiatan karyawan di gudang. dalam melaksanakan pekerjaan dan pengiriman produk mereka. Dengan layanan ekspedisi, maka tidak ada lagi kegiatan manual seperti pencatatan yang bersifat manual. Aplikasi ini dapat mempermudah kinerja layanan perusahaan baik dalam mengarsipkan dokumen ke file yang ada dan memiliki penyimpanan data yang telah terkomputerisasi dengan baik, sehingga dapat meminimalisir terjadinya kesalahan pada posisi pengarsipan dokumen arsip dan kehilangan file, sehingga hasil laporan menjadi akurat dan dapat digunakan sebagai keputusan pendukung bagi pimpinan perusahaan.

Prosedur untuk surat masuk dimulai dari bagian gudang yang meminta produk ke bagian pembelian (purchasing), kemudian dari bagian pembelian untuk memesan produk yang dirujuk ke pemasok (supplier). Ketika pesanan pembelian telah disetujui dan siap dikirim oleh pemasok, maka pengiriman akan dilakukan baik menggunakan layanan ekspedisi atau kendaraan itu sendiri ke perusahaan. Pada bagian ini pengirim, baik layanan ekspedisi dan pemasok, mengisi formulir aplikasi sebagai bukti untuk dapat memasuki perusahaan yang akan diperiksa oleh departemen keamanan. Kemudian penjaga keamanan akan menerima dan memeriksa dokumen pengiriman. Jika produk sesuai dengan yang tercantum dalam daftar permintaan gudang, maka formulir dokumen pengiriman langsung diberikan ke gudang dan akan diperiksa kembali oleh bagian tersebut. Jika produk yang dikirim cocok, maka produk langsung pergi ke gudang stok. Tetapi jika barang tidak sesuai dengan produk yang dipesan, maka produk tersebut segera dikembalikan ke pemasok.

Selain mengatasi masalah dalam penerimaan produk, aplikasi ini juga akan dikembangkan untuk proses surat keluar untuk pengiriman produk olahan perusahaan Super Tata Raya Steel. Proses ini dimulai dengan permintaan untuk produk yang dibutuhkan oleh pelanggan (customer) untuk pemasaran dan pemesanan produk diberikan kepada PPIC. Setelah mendapat persetujuan dari bagian PPIC, maka akan segera diberikan kepada bagian produksi untuk memproduksi dan memproses produk pesanan dari pelanggan. Setelah barang selesai, itu diberikan ke gudang, yang kemudian memeriksa produk. Jika produk cocok maka produk segera dikirim. Dalam proses ini bagian gudang akan memasuki kategori produk dan layanan ekspedisi yang akan ditetapkan ke dalam aplikasi. Kemudian membuat surat perjalanan dan memeriksa oleh penjaga keamanan, maka barang tersebut segera dikirim ke pelanggan.

Sistem yang akan dirancang mampu meminimalkan terjadinya kesalahan dalam memasukkan data dan membuat laporan secara mudah sehingga tidak membutuhkan waktu lama dalam penyajian informasi dan menjadi lebih efisien. Dalam menganalisa sistem yang diajukan, penelitian ini menggunakan Paradigma Visual untuk UML sebagai perangkat lunak untuk merancang use case diagram sesuai dengan kebutuhan perusahaan dan secara deskriptif memberikan penjelasan apa saja yang dilakukan oleh pengguna atau admin dalam mengelola 
sistem aplikasi. Langkah desain selanjutnya adalah membuat activity diagram yang menggambarkan aliran sekuensial atau urutan aktivitas dari use case diagram sebelumnya.

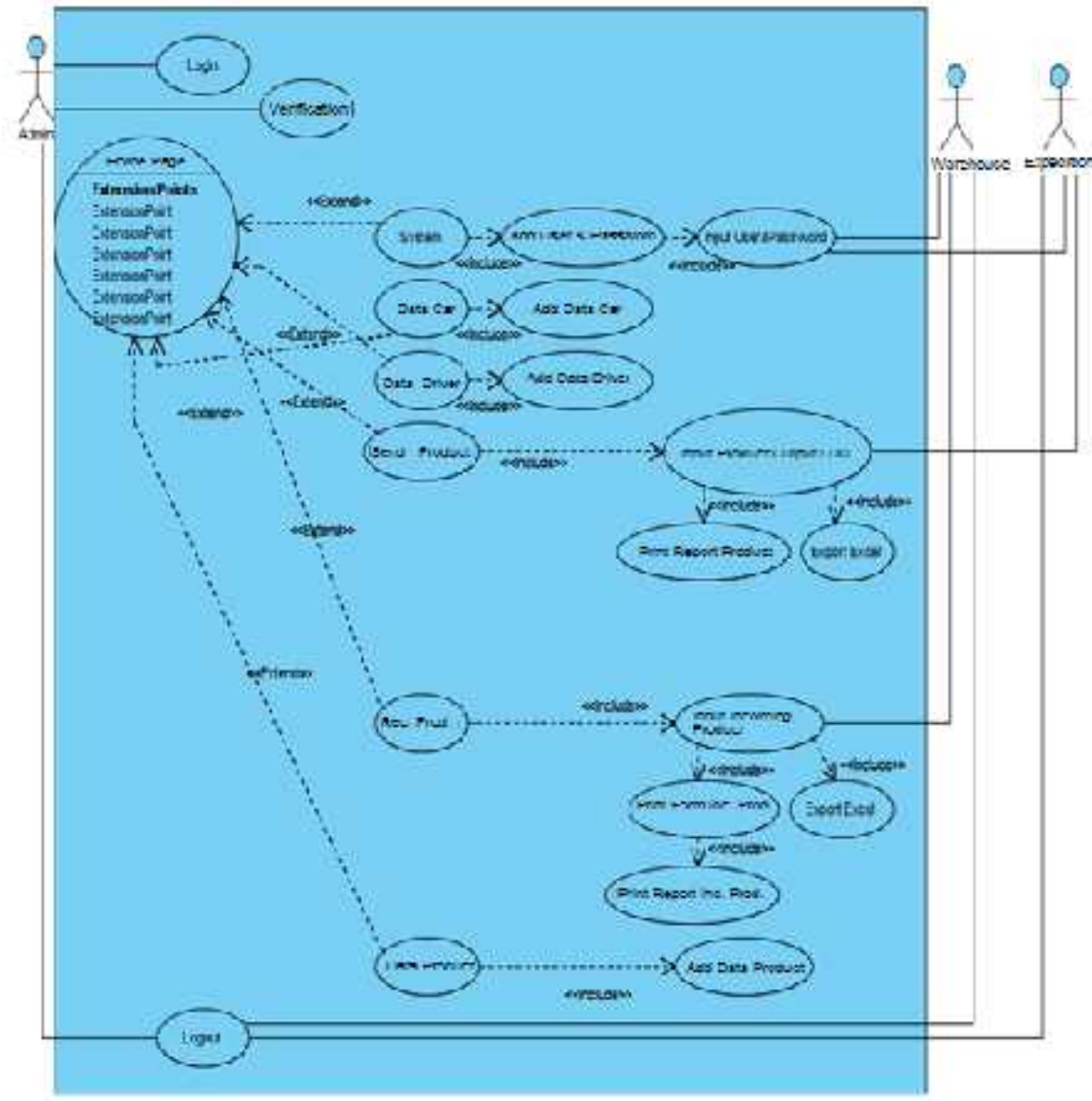

Gambar 2. Use case diagram

Tahap desain selanjutnya adalah membuat class diagram yang menggambarkan proses objek yang dapat berinteraksi melalui pengiriman pesan dalam pelaksanaan kasus penggunaan atau operasi tertentu sebelumnya. Pembuatan class diagram menggambarkan struktur objek sistem yang menunjukkan kelas sebagai komponen dari sistem dan hubungan antara entitas dan ini adalah apa yang akan digunakan sebagai desain database dan antarmuka bagi pengguna (user interface).

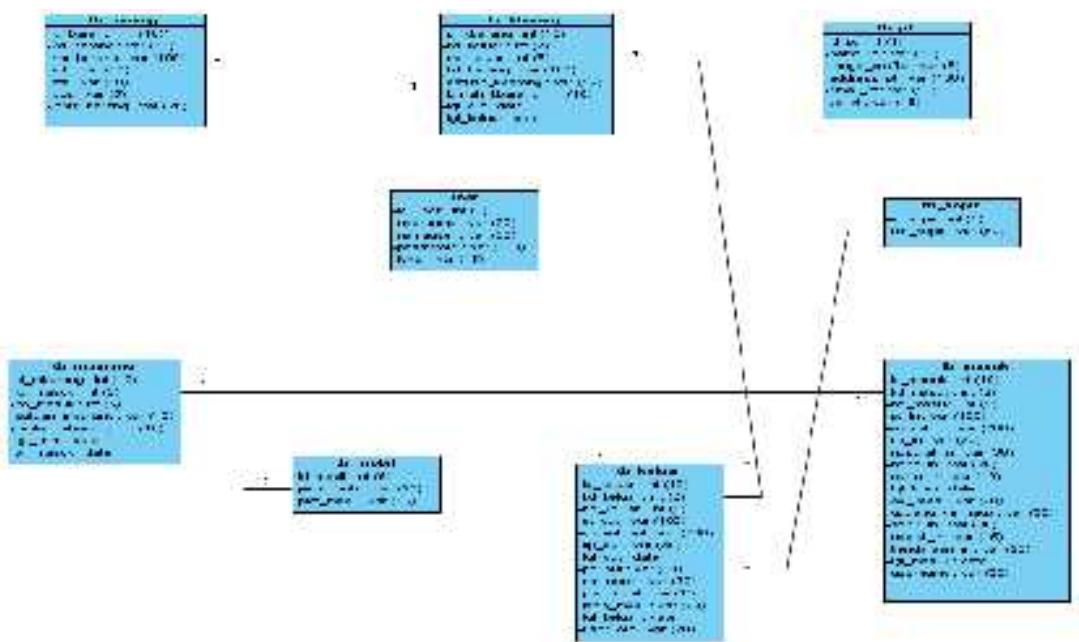

Gambar 3. Class diagram 
Perangkat keras yang diusulkan dibuat berdasarkan persyaratan sistem saat ini. Konfigurasi yang digunakan dalam desain sistem yang diusulkan adalah komputer dan printer. Selain perangkat keras, ada beberapa perangkat lunak pendukung untuk membuat aplikasi adalah Visual Paradigm 6.4 Enterprise Edition, editor, XAMPP dan frameworks yang mendukung desain aplikasi $\mathrm{B} 2 \mathrm{~B}$, tetapi penelitian ini lebih cenderung memilih native framework.

Selanjutnya, tahap desain antarmuka pengguna menggunakan bahasa pemrograman PHP yang dikombinasikan dengan beberapa kode HTML dan CSS untuk memiliki tampilan yang lebih menarik dan mudah digunakan atau user friendly. Tampilan ini akan terhubung ke database MySQL agar dalam pembuatannya lebih mudah, lebih ringan dan dapat bermigrasi dengan beberapa bentuk format laporan seperti Excel dan csv.

Dalam desainnya, aplikasi terdiri dari beberapa level tingkatan. Hal ini merupakan langkah antisipasi dengan cara preventif karena beberapa pengguna akan memasuki aplikasi ini, seperti ada level admin, bagian pengguna dari gudang dan layanan ekspedisi yang mengirim produk. Gambar 4 di bawah ini adalah ikhtisar dari tampilan halaman utama dari aplikasi untuk bagian admin, yang bagian ini dapat menyertakan atau memiliki hak akses penuh ke aplikasi ini, dari membuat master data pengguna, layanan ekspedisi dan sebagainya.

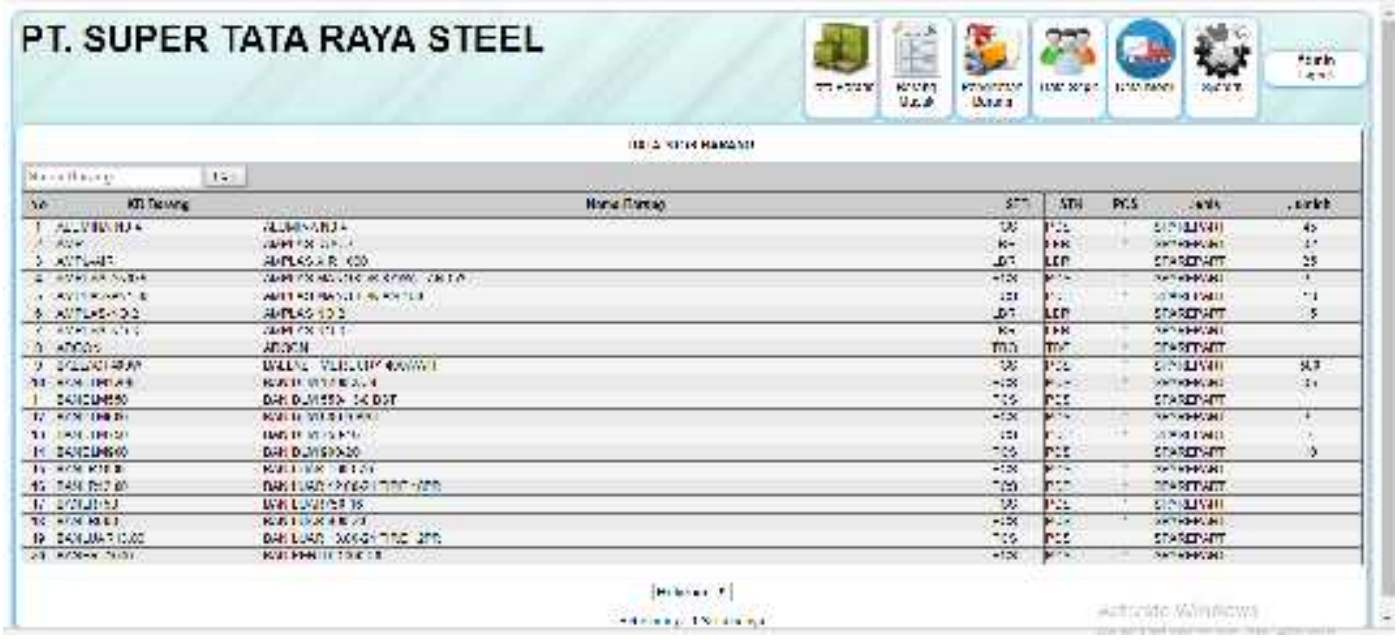

Gambar 4. Halaman utama departemen pergudangan

Hasil selanjutnya adalah gambar 5 yang menunjukkan tampilan form input untuk penerimaan produk dari layanan ekspedisi yang akan dimasukkan oleh pengguna dari departemen pergudangan.

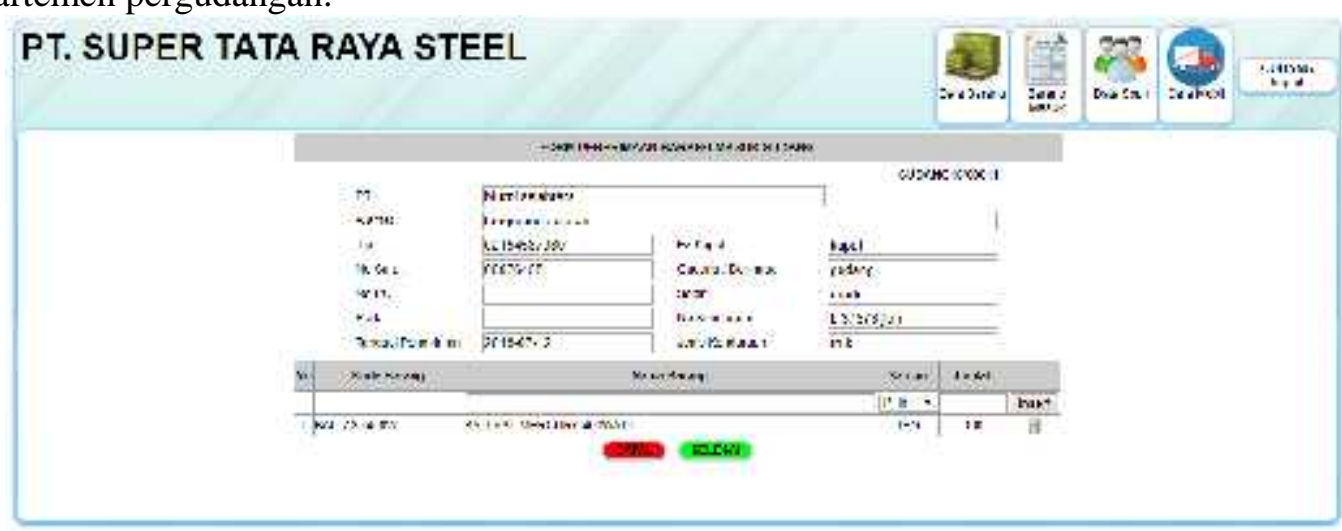

Gambar 5. Halaman data penerimaan produk departemen pergudangan 
Sedangkan pada Gambar 6 menunjukkan tampilan bentuk input untuk pengiriman produk oleh ekspedisi atau layanan pemasok yang terkait dengan pesanan pembelian yang dibuat oleh departemen pembelian (purchasing).

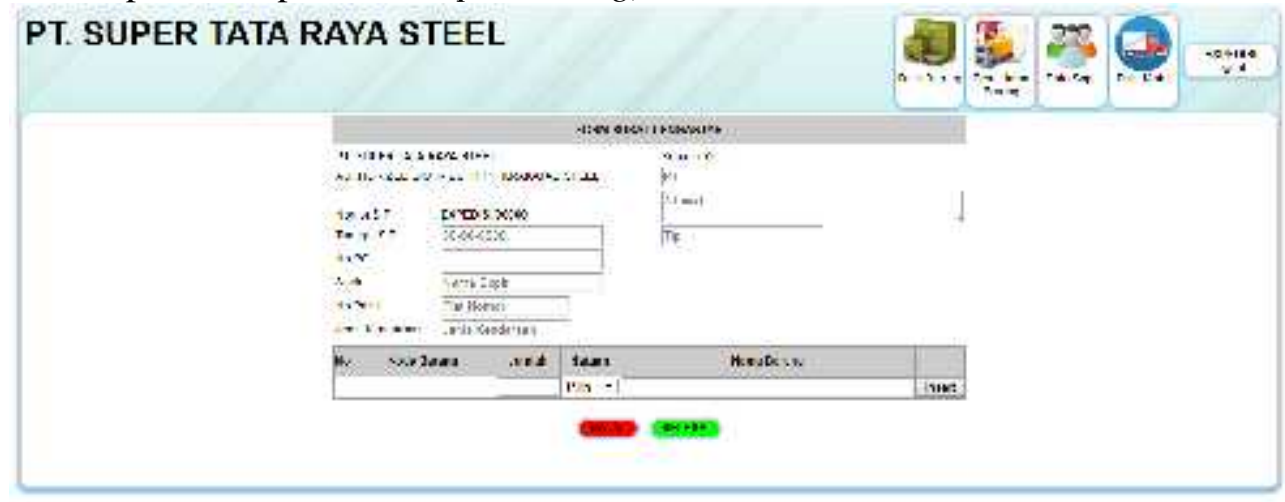

Gambar 6. Formulir surat pengantar untuk jasa ekspedisi

Agar sistem informasi mendapatkan hasil maksimal dan keamanan yang berkualitas dalam proses implementasi, proses pengujian yang dapat dilakukan dengan menggunakan metode black box testing. Tes ini dapat dilakukan pada aplikasi B2B yang telah dirancang untuk mendukung keputusan bisnis strategis bagi pemimpin perusahaan. Berdasarkan hasil pengujian dapat dinyatakan bahwa sistem telah valid semua dan tidak ada yang menyatakan kesalahan saat pengujian.

Dalam memasukkan formulir penerimaan produk, petugas gudang hanya harus membuka sistem dan memeriksa produk. Tugas ini harus dilakukan oleh bagian gudang. Selanjutnya, untuk memasukkan surat pengantar atau formulir keluar hanya sederhana, yaitu dengan membuka sistem pengiriman produk, sistem secara otomatis memasukkan surat pengantar dari bagian yang relevan. Kemudian dalam proses penyimpanan data, sistem menggunakan database sehingga dalam penyimpanan datanya hanya membutuhkan waktu yang singkat dan tidak akan memakan banyak tempat, adapun penyimpanan arsip data dari aplikasi ini yaitu menggunakan database MySQL, sehingga dalam proses pencarian data akan lebih mudah dan lebih akurat.

\section{KESIMPULAN}

Berdasarkan hasil perancangan dan pembahasan perancangan sistem aplikasi ini, dapat disimpulkan bahwa sistem manajemen sebelumnya masih manual, sehingga sulit bagi staf gudang untuk mengelola data arsip yang sudah ada sebelumnya. Oleh karena itu, pengolahan data akan mudah hilang dalam pemrosesan, sehingga pengarsipan data tidak lengkap. Perancangan aplikasi dengan konsep business-to-business diperlukan, basis data yang telah terintegrasi dengan aplikasi menghasilkan akses informasi yang lebih efektif dan akurat, kemudian data disimpan dan didokumentasikan dengan sangat baik sehingga tidak ada kerugian bagi perusahaan.

\section{SARAN}

Aplikasi berbasis web adalah pilihan tepat yang digunakan oleh perusahaan. Dengan sistem komputerisasi yang dilakukan pada saat proses memasukkan tanda terima produk dan proses pengiriman produk keluar, dapat dikerjakan dengan lebih mudah dan tidak memakan banyak waktu. Sehingga untuk melihat laporan dalam pengajuan produk masuk dan keluar tidak mudah hilang dan disimpan dalam komputer server. Dengan demikian, aplikasi ini juga dapat mendukung keputusan untuk pimpinan perusahaan sebagai kebutuhan dalam strategi bisnis. 
Penelitian lebih lanjut akan dikembangkan sehingga dalam implementasi penunjang keputusannya dapat menggunakan Online Analytical Processing (OLAP) [10] dan seiring dengan banyaknya data dapat membentuk pola-pola yang dapat diprediksi dengan pendekatan dari konsep data mining [11].

\section{UCAPAN TERIMA KASIH}

Terima Kasih kepada rekan-rekan STMIK Raharja yang telah mendukung dalam penelitian ini dan memberikan masukan-masukan yang positif.

\section{DAFTAR PUSTAKA}

[1] Sudaryono, U. Rahardja and A. Roihan, "Design of Business Intelligence in Learning Systems Using iLearning Media," Universal Journal of Management, vol. 5, pp. 227-235, 2017.

[2] M. Goul, "Business Intelligence at the crossroads: Convergence or confusion ahead?," International Conference on Information Technology Interfaces (ITI), Cavtat, pp. 21-28, 2010.

[3] K.H. Yang, C.H. Yuan, J.J. Guo, "B2B Platform Development in Electronics Manufacturing Supply Chain of China," International Conference on Management of Engineering and Technology (PICMET), Portland, pp. 1-7, 2017.

[4] E. Zunic, A. Besirevic, R. Skrobo, H. Hasic, K. Hodzic, A. Djedovic, "Design of optimization system for warehouse order picking in real environment," International Conference on Information, Communication and Automation Technologies (ICAT), Sarajevo, pp. 1-6, 2017.

[5] Hendra, E.S. Rini, P. Ginting, B.K.F. Sembiring, "Impact of eCommerce service quality, recovery service quality, and satisfaction in Indonesia," International Conference on Sustainable Information Engineering and Technology (SIET), Malang, pp. 35-40, 2017.

[6] A. Roihan and R. Fitriani, "Pemodelan Knowledge Managemen Service Kendaraan Berbasis Web Pada Bengkel Motor Sekolah Kejuruan," CERITA (Creative Education of Research In Information Technology and Artificial Informatics), vol. 4, no. 2, pp. 121129, 2018.

[7] S.P. Ribeiro, V.R. Santos, C.S. Pereira, "eCommerce business-to-business platform for the footwear sector: The cluster of Felgueiras," Iberian Conference on Information Systems and Technologies (CISTI), Caceres, pp. 1-6, 2018.

[8] G.P. Scheneider, Electronic Commerce 10th Edition, Boston: Cengage Learning, 2012.

[9] J. Yang, C. Liu, M. Teng, J. Chen, H. Xiong, "A Unified View of Social and Temporal Modeling for B2B Marketing Campaign Recommendation," IEEE Transactions on Knowledge and Data Engineering, vol. 30, pp. 810-823, 2018.

[10] A. Roihan and A. Maksum, "Konsep Data Mart Dalam Implementasi Sistem Job Fair Menggunakan Metode Online Analytical Processing Pada Dinas Tenaga Kerja," Semnasteknomedia, vol. 6, no. 1 pp. 2.10-61 - 2.10-66, 2018.

[11] A. Roihan, Karwandi and L. Listiyoko, "Development of a website-based decision tree system in data mining concept," IEEE Third International Conference on Informatics and Computing (ICIC), Palembang, 2018. 